Theoretical and Applied Economics

Volume XXII (2015), No. 3(604), Autumn, pp. 219-230

\title{
Towards a sustainable economy
}

\author{
Silvia Elena IACOB \\ Bucharest Academy of Economic Studies, Romania \\ popescusilviaelena@yahoo.com \\ Constantin POPESCU \\ University Valahia of Targoviste, Romania \\ constantinpop1967@yahoo.com
}

\begin{abstract}
Studies and researches on the deterioration of the ecosystems and the environmental services provided by the natural ecosystems have been undertaken and are under way even to this day on very many levels, some even in areas or domains having no connection with ecology or with the environment. The profound ecology demonstrates unequivocally that the natural and semi-natural ecological ecosystems produce resources and services, through the concentration of the solar radiant energy and trough the maximization of the density of the energy flow. The primordial task the research have is the creation of a vision as widely accepted as possible on a sustainable society in the long run.
\end{abstract}

Keywords: ecosystem, natural capital, sustainable development, socio-economic system, sustainable economy.

JEL Classification: O1; O3; P2; Q5; R5. 
All the systems that make up the natural capital preserve the function of production of resources and services based on the fundamental ecological processes. This is why the energy flow coming from the solar radiant energy - which is free - and the recycling of the nutrients, namely the fundamental mechanism for maintaining the bio-geo-chemical circuits, are defining elements of the structure of the natural capital and of the ecological processes that generate products and services.

The preservation of the spatial and temporal organization, of the productive function, and also the control of the dynamics of these ecological systems, is realized only if the direct and significant intervention of the human populations actually controlling the socioeconomic system is permanently maintained in the clear, namely within the limits of the supporting capability of the ecosystems, which are also the limits of their stability domain.

The daily reality shows that the anthropic intervention is direct both during the stages of creation of these types of ecological systems through the actual removal or total elimination of the components of the natural ecosystems and by the influence on some physical and chemical systems and especially on the bio-geo-chemical mechanisms starting with the sowing or plantation stages, species amelioration, fertilization, fighting pests etc., without which the ecosystems are practically disconnected from the functional hierarchy called environment.

One cannot approach correctly the issues related to the condition of the ecosystems and the use of the resources without taking into consideration at least three perspectives, triggered by different approaches of the environment:

- The economists' approach: they try to maximize welfare taking into account the constraints determined by the existing capital and by the level of the technologies. Along this line, the economists are rediscovering at present the importance of the natural capital and are trying to evaluate its products and services;

- The ecologists' approach: they emphasize the need to preserve the integrity of the ecological systems, which are all indispensable for the general stability of the global ecosystem. A more realistic approach accentuates the need to preserve these systems' elasticity and dynamic capacity of adapting to change, in answer to the pressure of the command factors, and not the need to preserve an "ideal" static state;

- The sociologists' approach: they underline the importance of the human nature, of the main "actors" and of the modes of social organization, both of them being determining for the discovery of some viable means of realizing a sustainable development; the experience shows that not giving enough attention to the social factor may endanger the efficacy of the different economic development projects and programs.

The present report is a debate that brings together all the three perspectives mentioned above, and the solutions mainly rely on the economic instruments for the organization of a sustainable development, yet, at the same time, try to integrate the ecological and social dimension of any enterprise.

An extremely important and complex problem facing both the developing and the industrialized countries is related to the discovery of the answer to the following simple 
question: can one support the economic growth, namely the increase of the Gross Domestic Product per capita without damaging the environment?

This difficult problem cannot be approached except with the help of the concept of sustainable development

We need to mention from the beginning that the economic development is the increase in time of the general level of prosperity of the society, and the economic growth is the process of increasing the economy's capacity of producing goods and services, being the result of the growth of the volume of the production factors in use, of the increase of their qualitative level and of the efficiency of their use.

Consequently, the economic growth contributes to the development by providing supplementary goods and services, yet it represents just a part of the development.

\section{Evaluation of the impact on the environment}

The general goal of any research related to the condition of the ecosystems or the condition of the environment in general needs to include the identification and the analysis of the correlations between the macroeconomic or sectorial policies and the environment.

At the same time, the integration of the economic analysis with the ecological analysis of the investment projects, in order to promote policies orienting the public and private initiatives and investments on the way towards sustainable development supposes:

- substantiating the imperative of introducing the studies evaluating the impact even since the incipient stage of the projects;

- presenting the methodology for the integration of the studies evaluating the impact, in the economic analysis of the projects;

- identifying the possibilities of turning to good value the inputs (factors) and outputs (results) with no price on the market;

- identifying and examining some non-economic indicators used in the decisions related to the project;

- presenting the methodology for using multi-criteria analyses in selecting and evaluating investment projects.

In general, the environmental impact means any modification, be it positive or negative, of the environment, determined partially or as a whole by the activities, products or services of an organization.

It results that the study evaluating the environmental impact represents a formal study, whose aim is to estimate the environmental consequences triggered by the activities, products or services of an organization.

The departure point in the determination of the environmental protection priorities, under the conditions of the resource limitation, is the determination of the costs triggered by the environmental damage and the benefits resulted from a good management and the use of these elements in the decisional process. 


\section{Natural capital. Renewable and non-renewable resources}

The definition of the natural capital via the way of perceiving the physical, chemical and biological environment, as representing the totality of the natural and semi-natural ecological systems, permits a new approach of the management of the ecological systems.

The natural ecological systems are, in this case, interpreted as self-maintained systems on which the direct anthropic influence is absent or very limited, in general, triggered by activities meeting the basic needs of the local population, research needs and, more recently, ecotourism.

The semi-natural ecological systems are represented by systems which, although bearing a direct anthropic influence, for instance the industrial exploitation of the renewable resources, preserve the structural and functional features by which they produce resources and services, maintain themselves and grow.

The basic feature of the natural and semi-natural ecological systems is that their productivity and stability does not need a supplementary input of energy produced in other systems.

The direct activities of exploitation of the resources from the semi-natural systems or the activities of control of certain command factors require a current management process. These ecological systems functioning in a semi-natural regime are represented by:

- the agro-systems responsible for the production of cereals, vegetables, fruits, technical plants and fodder plants;

- secondary forests or forest plantations for the production of wood;

- animal farms, for the production of food of animal origin and raw matter for the leather industry, farms for aquaculture in general, and for intensive fish breeding, in particular;

- storage lakes created for the exploitation of the hydro-power potential, as a renewable water source and for the exploitation of the fish-breeding potential etc.

The anthropic intervention is direct both during the stages of creation of these types of ecological systems through the actual removal or total elimination of the components of the natural ecosystems and the alteration of some physical and chemical environments and especially of the bio- geo-chemical mechanisms beginning with the stages of sawing and plantation, species improvement, fertilization, pests elimination etc.

We will underline the fact that the semi-natural ecological systems produce resources and services, through the concentration of the radiant solar energy and the maximization of the energy flow density. For example, the humid areas are ecological systems with an intermediate position between the land and water systems, and they are characterized by their capacity of cleaning the surface waters, due to mechanisms generated by the fact that, for instance, periodically or permanently, the soil is covered by hydrophile (waterloving) species, in which a specific fauna, able to recycle the nutrients, develops.

Practically, however, most of the natural and semi-natural ecosystems are intertwined, both with one another and with the anthropized ecological systems. 
All the systems that make up the natural capital preserve their function related to the production of resources and services relying on the basic ecological processes. For this reason, the energy flow from the radiant solar energy, which is free, just as the recycling of the nutrients - the fundamental mechanism for the maintaining of the bio-geo-chemical circuits - are defining elements of the structure of the natural capital.

At the same time, it is considered that the maintaining of the spatio-temporal organization, of the productive function and also the control of the dynamics of these ecological systems are realized only if the direct and significant intervention of the human populations is assured permanently and in a non-damaging way.

Seeing their strict dependence on the direct and complex intervention of the human populations, associated to a flow of auxiliary energy produced in the energy conversion systems, it can be stated that these ecological systems have structural and functional features specific to the anthropized systems and, consequently, we consider them part and parcel of the structure of the socio-economic systems.

In fact, a third of the total of the agro-systems, for example, are intensive and superintensive production structures, calling for a very significant auxiliary input of energy, which can reach values of $10 \mathrm{kcal} / \mathrm{m}^{2} /$ year. Therefore, such ecological systems are no longer natural or semi-natural; they are assimilated to the components of the capital built by the human populations.

Finally, this last category of ecological systems is considered as representing components of the natural capital dominated and controlled by the human populations and, consequently, we say that these ecological systems are subordinated from a structural and functional perspective to the development strategies of the socio-economic system, demonstrating in this way that they are practically integrated in the socio- economic system.

Moreover, as a piece of evidence supporting the resources depletion, it is considered that the weight of this category of ecological systems has grown exponentially during the last century, simultaneously to the demographic growth and especially to the increase of the basic needs of the human societies, and the numerical growth of these systems is evidently the result of a process of substitution of the natural and semi-natural systems.

We do not exclude, therefore, the possibility of substituting, within certain limits, some components of the natural capital, by others, in order to increase productivity, yet the substitution accompanied by the significant growth of the energy flow produced in other processes is not acceptable.

The comments on the extremely controversial issue, regarding, on the one hand, the possibility and the opportunity of substituting the components of the natural capital by components created by the human populations and, on the other hand, the obligatory request of guaranteeing their complementariness should lead to the conclusion that always the normal evolution is towards the harmonization of the spatial relations and of the matter and energy flows between the natural capital and the socio-economic system. 
We shall reiterate the fact that all the components, in a natural, semi-natural and anthropized regime, are dissipative systems, which maintain and maximize the energy flows and which recycle the raw matter, producing resources and services.

In this way, all the ecological systems are dynamic on large, geological timescales and develop by going through different growth stages, depending on which they produce resources and services. It results, logically, that on large, ecological and geological timescales, all the resources are renewable. Yet, the management of the socio-economic systems relies on strategies emitted for much shorter timescales, namely 5-15 years, so in this case their management cannot be operable by comparison to the timescales at which the resources are renewable.

This is why in the category of the renewable resources we can only include the vegetal and animal biomass, most of the soils and water reserves and partially the mineral resources usable as construction materials.

The ores and the fossil fuels such as coal, oil and natural gas have a replacement time of the order of several hundred thousand or million years, which determines their inclusion in the category of the non-renewable resources.

From a managerial perspective, the distinction between renewable and non-renewable resources is extremely important, because it leads to the conclusion that the renewable resources need strategies for the conservation of the functional integrity and productivity of the components of the natural capital, maintaining the exploitation rate under or very close to the rate at which these resources are produced. For the non-renewable resources, however, flexible strategies are needed, which should include measures for the limitation of the exploitation rates, the identification of alternative sources and especially, technical measures for the bio-geo-chemical recycling of the products obtained and of the residues.

One of the essential features of the natural capital, which has almost always been neglected, is its structural and functional diversity.

The presentation of the problems up to this stage allows us to highlight the structural and functional aspects of the ecological systems, which are in fact arguments in the substantiation of the new socio-economic development model, namely the sustainable development.

Consequently, the new way of development does not suppose only the need of maintaining the natural capital as weight above a critical level, but supposes especially the need for it to preserve its maximum level of structural and functional heterogeneity, on which the long term development opportunities will actually depend.

Consequently, the issue of the conservation of the biological and ecological diversity is not a collateral problem representing just a difficulty for the political decision-makers, but it is actually the very problem of the conservation of the natural capital as support of the development and guarantee of the sustainability. 
The last 2-3 decennia of the last century have been marked, incomparably more than any other period in mankind's history, by the obvious process of deterioration of the environment, noticeable through the toxic, often lethal effects of the secondary and final products resulted from the processes of the socio-economic systems. These products have gathered together and have been concentrated in the major environmental spheres (troposphere, lithosphere, and hydrosphere) and have damaged the taxonomic hierarchy of the biosphere, simultaneously to the degradation of the abiotic environment.

\section{Towards a sustainable development}

The reactions to the tendencies of degradation of the environment through damaging anthropic activities have diversified, by and by, as the effects have been perceived, evaluated and correlated to a series of concrete human activities. Consequently, different, increasingly diverse actions have been designed to delimit the pollution effects and, very recently, to decrease and prevent pollution.

To the tendency of alarming increase of the process of elimination of different plant and animal species, a phenomenon generating a worrying narrowing of the biodiversity, it has been answered, at first, mainly by actions of identification of the vulnerable and endangered species and through the elaboration of some special protection programs for them. At the same time, for the endangered habitats, actions of ecological reconstruction have been taken, avoiding in this way the imminent elimination process.

The real process of erosion of the biological diversity following the aggressions of the socio- economic system could not be stopped using sectorial protective approaches related to certain species or the reconstruction of some endangered habitats. Therefore, organisms like the EU or UN have felt constrained to adopt regional or global conventions for protecting the biodiversity.

The restrained meaning of the biodiversity concept could be maintained by the supporters of the "development at all costs" until close to the beginning of this millennium, namely after the Rio de Janeiro Conference (1992).

The conclusions of the conference imposed the adoption of the "Convention on Biological Diversity", which, although adopted, signed and ratified by all the signatory states, is very hard to operationalize from one country to the next, before approaching and commenting on the coordinates and restrictions resulting from the application of this convention.

Two mentions are necessary, which will help us distinguish between biodiversity in a broad sense and biodiversity in a narrow sense, promoted by those supporting a "development at all costs":

1. For a long while, this concept designated only the richness of species without considering the diversity of the structural and functional units constituted by the abiotic environment.

2. The socio-economic systems, which include a great diversity of the social, cultural and patrimonial capital, were not taken into account when talking about biodiversity. 
It results that we can affirm the following possibilities:

- Actually, the broad sense of the biodiversity concept includes the totality of the organized units that constitute the natural capital, the human species and all the capital created by it.

- Under these circumstances, the diversity of the ecological and biological systems would be a more adequate term for the biodiversity concept in a broad sense.

Thus, the conservation of the biological diversity needs to be designed and realized based on strategies, programs and methods that pursue, on the one hand, a sustainable use, namely within the limits of the carrying capacity of the components of the natural capital, and, on the other hand, the management of the development of the socio-economic system, namely of the capital created by the human populations.

The extension and operationalization of the biodiversity concept was necessary because of the numerous attempts of narrowing the different forms of biological diversity, in order to defend new techniques of degradation of the ecosystems.

The approach of biodiversity according to the above-mentioned plans generated numerous controversial debates, organized mainly by international organisms of this domain such as FAO, UNESCO, the European Council, debates that involved, on the one hand, governmental experts, and on the other hand, representatives of the scientific research and of the international funding organisms. Unfortunately, the governmental experts and the experts of the important funding bodies still have the tendency to interpret biodiversity restrictively, defending the view that the degradation of the environment is a normal process accompanying the technological development and the solution can be found by new developments.

We need to mention that the summits from Rio, Johannesburg, Copenhagen and many other meetings on a regional level or with a more restrained attendance prove that the political decision-makers have understood to give up on speculative arguments and have found themselves forced to adopt, at least formally, clear measures for the prevention of the environmental degradation.

The political decision-makers, as well as the managers, have been obliged to admit that important for the long-term development is the creation of the conditions needed for a sustainable development and implicitly for the conservation of the biodiversity.

The acknowledgement of this necessity on a large scale has been defended at least by the following arguments:

- The effort for the preservation of the biological diversity cannot focus only on the natural ecological systems, based on the reason that they would integrate almost all the species, of which most are still not studied.

- It is necessary to also preserve, to the same extent, the habitats assuring the complex fundamental ecological processes and, naturally, to avoid the elimination of certain species.

The conservation or maintaining of the structural-functional integrity within the stability domain of a given natural or semi-natural ecological system involves, to the same extent, 
the maintaining of the course of the dynamics of the abiotic and biotic sectors but also of the interactions between them.

Thus, the term of interconnectivity has been introduced, which represents the necessity of a permanent intercommunication of the components, in the sense of support for life, one for the other.

Consequently, when the development of each ecological system is analyzed as a complex long-term process, the general tendency is to assure the mechanisms by which the number of species or populations may increase, without taking into consideration the need of having, within, them, specializations and interactions able to increase the environmental services, such as maximizing the energy flow, recycling the nutrients, regulatory mechanisms, balance and stability mechanisms etc.

The result of such a process appears, therefore, in the extension to the spatial scale of the stability domain, and the analysis on a time scale specific to large systems would be obligatory.

It results that by no means can one talk about the existence of useless species in the context of a complex model, but in different growth stages, the functioning of the ecosystem successively relies on one or the other of the species included in the taxonomic hierarchy.

Consequently, even though at the same time, not all the distinctive elements are equally important at the spatio-temporal scale at which the ecosystem is analyzed, every species has its distinct role.

It results, logically, that for the preservation of the ecological structure on the scale of the national and macro-regional complexes, it is necessary to take into account the maintaining of a mosaic of natural and semi-natural systems, which should include all the types of ecosystems and preserve at least half of their surface. The preservation of the ecological systems therefore involves their interconnectivity, which is assured by natural corridors or, where they are missing, such corridors should be reconstructed technologically and ecologically.

The connectivity of the natural and semi-natural systems is an essential condition for the spreading of the species within their area, for their movement, for the directions of the new gradients modified because of the climate changes, the consideration of the elements highlighted actually requiring operational policies and strategies on the level of the states or state unions.

The European Council has established, on the occasion of the reunion of the environmental ministers from Sofia in 1996, that, on the European level, it is necessary to create a European network of ecological systems interconnected by means of management programs, which should comprise the preservation of the natural and seminatural systems specific to the different European regions, the reconstruction of some endangered habitats, the rehabilitation of certain ecosystems and also special sustainable management programs for the anthropized systems. 
The development specialists have begun to rethink the strategic directions, trying to reconcile the economic growth and the biodiversity preservation in a credible manner. As long as everything remains on a declarative level, eventually with small positive examples in an ocean of degradation of the natural substratum, it is obvious that what is needed is a change of paradigm. Regional planning means understanding the dynamics of the processes, understanding the relations and the interdependences and establishing the values we care for, aware that our survival is not possible in their absence. Often, the same piece of land is desired by the farmers, by those crazy about developing the infrastructure and by those who wish to preserve the natural values and the ecological coherence. In this competitive process, it is possible to win the preservation of the natural values, yet in general, the major interest in the long run, namely of maintaining the ecological substratum, is lost to the minor momentary interest of creating parking lots and golf courses.

All these are necessary since the diverse biological systems actually hold a huge genetic fund, an immense genetic information bank, a fund assuring, on the one hand, the natural process of species dynamics, and, on the other hand, information for the technological research concerning the correct dynamics of the anthropized systems and the correction of their trajectories, by imitating nature.

Very recently, the term bio-industrial development or bio-geo-eco-development has emerged, in the sense of avoiding the negative tendencies generated by the idea that man rules over nature. It is therefore admitted that the anthropic factor, though being the command sub-system, is part and parcel of the system.

Moreover, during the last decennium, there has emerged the idea of creating a complementariness between the top industries of the developed countries and the diversity of the genetic resources of the underdeveloped countries, in the sense that by the "Convention on Biological Diversity" the developed states committed to returning at least $20-25 \%$ of the profits obtained through the exploitation of the genetic patrimony to the underdeveloped countries.

These financial resources would have the role of financing the increase of the surfaces of the so-called "protected areas", namely the very preservation of this invaluable genetic patrimony, the main support of life on our planet.

\section{Conclusions}

The very recent research has approached the issue of the ecosystems' carrying capacity, a problem addressed by both the specialists in demography and the specialists in human ecology, to be able to estimate, based on scientific grounds, the limits of the natural development and demographic growth.

The carrying capacity is a feature of every ecological system or category of ecosystems, depending on their development stages and the hierarchic level they are part of. Consequently, the carrying capacity is the concrete expression of the stability domain 
expressing the ability of the ecosystem of changing its structural and functional parameters under the influence of the command factors.

The stability domain of an ecosystem designates the direction in which it is developing, with the mention that the process unfolds at very large time scales, of over 100 years and that it is reversible, whenever a strong impact is exerted on the system by external factors.

It results, in this context, that the notion of "carrying capacity" actually concerns the functioning capacity of the large, complex and dynamic systems, such as the ecological systems.

At the same time, to each ecological system one can associate a certain productive capacity on the goods and services production level. This capacity is concretely expressed depending on the fluctuations of the command factors, namely on the trajectory the systems are following.

Thus, in any socio-economic system, a healthy, namely sustainable, growth, has to be calibrated in the sense of its harmonization with the productive and carrying capacity of the natural systems, which assure both the matter and energy resources, and a series of services on which the health of the human population depends.

Starting from these considerations, one can state that the development of the society, supported by the economic growth, is healthy only if this growth gradually changes, by and by, as the limits of the carrying and productive capacity of the natural capital are attained, via a structural and functional improvement process.

The process needs not suppose either the increase of the matter and energy flows from the natural systems to the socio-economic systems or the storage of wastes inside the socioeconomic system and dangerous substances in the environmental components such as the troposphere and the hydrosphere.

At least during this stage, when numerous aggressions on the natural capital can be noticed, the management of the socio-economic system needs to suppose an alternation between the economic growth and the structural and qualitative improvement, which means the ecological reconstruction of certain degraded environments that cannot be otherwise rehabilitated. By means of ecological reconstruction actions it will be possible to cover, at least in part, the debt of the socio-economic system to the environment and, on this basis, the premises of new growths will be created.

\section{Acknowledgements}

This work was cofinanced from the European Social Fund through Sectoral Operational Programme Human Resources Development 2007-2013, project number POSDRU/159/1.5/S/142115 „Performance and excellence in doctoral and postdoctoral research in Romanian economics science domain" 


\section{References}

Allan, D., 1994. Stream Ecology. Oxford. London.

Chiras, D., 1991. Action for a Sustainable Future. Redwood. USA.

Constantza, R., 1996. Gross world product from International Monetary Fund (IMF). World Economic Outlook. October 1996. Washington. DC.

Constantza, R., 1997. The Development of Ecological Economics. London.

Kula, E., 1994. Economics of natural resources, the environment and politics. Second edition. London.

Leopold, A., 1949. A Sound Country Almanac. Oxford. London.

Lester, R. Brown, et al., 1997. State of the World and our Resources. New York: W.W. Norton \& Company.

Myers, N., 1993. The World's Forests: Problems and Potentials (Corvallis, OR: Pacific Rivers Council, 1993).

Odum, E., 1993. Ecology and our endangered life-support system. Sunderland. Philadelphia.

Popescu, C., 1998. The need for settlement ecological forestry principles in Romania. The 23th Congress ARA. Rochester. New York.

Popescu, C., 1999. Protection and integration of the forest heritage of Romania-a problem of national and regional policy. The 24th Congress ARA. Liege.

Popescu, C., 2000. Strategies in the management of forest ecosystems. International Seminar Transition Management. INCE. Bucharest.

Popescu, C., 2000. The balance of agro-forest-pastoral-an attempt at reconciliation between agriculture and forest. The $25 \mathrm{~h}$ Congress ARA Cleveland. Ohio. SUA.

Popescu, C., 2000. Sustainable use of forest resources and the challenges of the future Romania. Romanian Academy. Bucharest.

Popescu, C., 2002. Principles and criteria for sustainable management of forest ecosystems, The 27th Congress ARA. Oradea. Romania.

Popescu, C., 2008. The growth of the forest ecosystems role for the defence of the environmental components. The 32nd Congress ARA. Boston. USA.

Popescu, C., 2008. Conflicting conditions arising from abusive exploitation of the forests of the world. Bibliotheca Press. Târgoviște. Romania.

Sullivan, F., et al., 1995. The Timber Trade and the Degradation of the World's Forests. London: Earthscan Publications.

Tamas, St. and Ionescu, M., 2002. Elements of computer science. For Life Press. Brasov. Romania.

Vădineanu, A. 1998. Sustainable development. Press University of Bucharest. Romania.

Vădineanu, A., Negrei, C. and Lisievici, P., 1999. Sustainable development. Press University of Bucharest. Romania. 